\title{
A RETÓRICA NA APLICAÇÃO DA JUSTIÇA E A RUPTURA COM O IDEAL RACIONALISTA MODERNO
}

\author{
RHETORIC IN THE APPLICATION OF JUSTICE AND \\ BREAK WITH MODERN IDEAL RATIONALISTIC
}

\author{
FLÁVIO HENRIQUE FRANCO DE OLIVEIRA ${ }^{1}$ \\ PAULO ADALBERTO FRANCO DE OLIVEIRA ${ }^{2}$
}

\begin{abstract}
RESUMO: O presente trabalho parte da constatação de que um dos grandes desafios da humanidade é criar um instrumento capaz de amenizar as desigualdades sociais e ao mesmo tempo dar segurança jurídica à sociedade. Este estudo analisa a formação dos mecanismos operacionais do direito, demonstrando o modelo proposto por Chaïm Perelman, que busca através da retórica o conteúdo para compreender a realidade, cuja contribuição é a quebra das fronteiras da razão, consequentemente, atraindo para uma reflexão sobre o novo paradigma da justiça. E, para isso, expomos a doutrina racionalista, que fundamenta o princípio de que é possível chegar às verdades absolutas através da razão, logo, contrariando a retórica. Ao final, um paralelo entre as posições, o racionalismo e a retórica, procurando compreender que a solução para a problemática não se encontra nos extremos, más no equilíbrio entre os instrumentos operacionais.

PALAVRAS-CHAVE: Aplicabilidade da Justiça; Retórica; Racionalismo Moderno; Globalização.
\end{abstract}

ABSTRACT: This work starts from the observation that one of the great challenges facing humanity is to create a tool to alleviate social inequalities while providing legal security to society. This study analyzes the formation of the operational mechanisms of law, demonstrating the model proposed by Chaim Perelman, to search through the contents of rhetoric to understand reality, whose contribution is breaking the boundaries of reason, therefore, to reflect on attracting new paradigm of justice. And for that, we expose the rationalist doctrine that underlies the principle that it is possible to find absolute truths through reason, then, contrary to the rhetoric. At the end, a parallel between positions, rationalism and rhetoric,

\footnotetext{
Artigo recebido em 08.02.2013. Pareceres emitidos em 09.09.2013, 13.11.2013 e 22.03.2014. Artigo aceito para publicação em 07.04.2014.

${ }^{1}$ Mestre em Direitos da Personalidade do UniCesumar - Centro Universitário Cesumar - Maringá/PR. Docente da FACO - Faculdade de Tecnologia de Cruzeiro do Oeste/PR e UNIPAR - Universidade Paranaense-Guaíra/PR. flaviofranco2006@hotmail.com

${ }^{2}$ Advogado. Graduado em Direito pelo Centro Universitário de Maringá/PR. Pós-graduado em Direito Aplicado pela Escola da Magistratura do Paraná - Londrina/PR. Mestrando UEL - Universidade Estadual de Londrina/PR.pf-oliveir@bol.com.br
} 
trying to understand that the solution to the problem is not at the extremes, bad balance between operational instruments.

KEYWORDS: Applicability of Justice; Rhetoric; Modern Rationalism; Globalization.

SUMÁRIO: Introdução; 1. A Nova Retórica de Chaïm Perelman; 2. Racionalismo Moderno; 3. A Problemática da Aplicação da Justiça; Considerações Finais; Referências.

SUMMARY: Introduction; 1 . The New Rhetoric of Chaïm Perelman; 2. Modern Rationalism; 3. The Issue of Application of Justice; Concluding Remarks; References.

\section{INTRODUÇÃO}

Percebe-se que os problemas que circundam a nossa existência, dentre eles as desigualdades sociais, embora global, é mais evidente em nações subdesenvolvidas, que sofrem com as consequências oriundas da formação histórica social. São várias as causas que contribuem para a condição de subdesenvolvimento, refletindo drasticamente no projeto de vida de cada ser.

A globalização cria novos paradigmas nas vidas das pessoas, modelo esse regido pelo reflexo da pós-modernidade, que tem obtido vulto catastrófico na sociedade contemporânea. Discutem-se variados temas em busca de um ponto de equilíbrio social, a fim de atingir conceitos primitivos e políticas humanas voltadas à melhora da qualidade de vida, consequentemente, reduzindo o impacto do caos oriundo de uma lenta formação cultural. O objetivo é conhecer ações para instituir uma sociedade mais justa, igualitária e harmônica.

Pergunta-se, então, quais as contribuições o direito, como mecanismo de equilíbrio social, é capaz de fornecer para supressão desta desigualdade ou, ao menos, amenizar o desequilíbrio do sistema social ? E, se isso é possível, qual a melhor moldura a ser utilizada? Através desse estudo, conjectura-se o subsídio do modelo proposto por Chaïm Perelman, como fator científico da dialética e retórica em contraposição à razão, como instrumento capaz de maleabilizar a solidez da problemática, cuja fundamentação teórica é multidisciplinar, permitindo, por si, a compatibilização de ideias. Por outro lado, procura dispositivo capaz de viabilizar segurança jurídica à sociedade, visto que a dialética não permite estabelecer padrões de comportamento estável. Portanto, o positivismo surge como oposição. Perquiri se essa segurança jurídica, em amplo aspecto, possui condição de melhorar o projeto de vida da sociedade. E, no mais, se o reflexo do racionalismo vigorante, como seguimento de pensamento que cultiva o princípio de que é possível chegar às verdades absolutas através da razão, possui espaço numa época de tão grandes diferenças culturais e sociais.

Justifica-se a escolha do tema pela relevância dentro da área jurídica e utilidade para o inicio de um raciocínio horizontalizado capaz de privilegiar parte significativa da sociedade, bem como, pelos fatores de pesquisa disposto 
dentro do plano temático, o qual prioriza o caráter interdisciplinar, visando uma integração em diversas áreas do conhecimento, tais como filosofia, direto, história, sociologia.

\section{A NOVA RETÓRICA DE CHAÏM PERELMAN}

Docente de lógica da Universidade Livre de Bruxelas, polonês naturalizado na Bélgica, Chaïm Perelman, é eminente na área da Filosofia do Direito, é um dos mais importantes teóricos da Retórica no século XX, em que materializa sua participação colaborativa no tocante à metodologia do direito, onde, através da Teoria da Argumentação, propõe uma aplicação prática dos juízos de valores $^{3}$.

Suas pesquisas sobre lógica de argumentos iniciam com a junção de uma série de escritos e teses nos campos eclesiástico e acadêmico, concluindo com método científico da dialética e retórica em contraposição à razão.

Seus pensamentos excedem a lógica, ultrapassa as fronteiras da antiguidade para teorizar, indiscutivelmente, todas as ciências e teorias da argumentação, conforme destaca Marcos Antônio Souza Alves:

A proposta de Chaïm Perelman de uma nova retórica pode ser considerada, mesmo depois de muitos anos de sua criação, a teoria mais completa e uma menção indiscutível em todos os estudos em teoria da argumentação e retórica. Deve a isso a posição única e fundamental que ocupa na história do pensamento filosófico, sendo seu nome geralmente associado à revalorização da retórica. Ao pretender desenvolver uma teoria da argumentação, Perelman se deu conta da importância dos antigos estudos de Aristóteles e, ampliando o campo da lógica, admitiu na esfera do racional também os raciocínios retóricos. Filiando-se claramente entre os neo-aristotélicos ${ }^{4}$.

A Nova Retórica é marcada pela redescoberta das Ciências GregoLatina, fundindo-se em técnicas argumentativas concatenadas através de demonstrativos práticos. Em grande perspectiva, teorizou que os argumentos não formais derivam dos princípios da teoria retórica e de considerações sobre os valores particularizados, definidos pelas prenoções ${ }^{5}$.

Estes argumentos alimentam-se das fontes do senso comum, universalmente considerados e admitidos, seria como um foco central de fatores aceitáveis comumente pela sociedade em que traçam as margens da razão. Tal princípio é reconhecido pela adesão que dão aos conflitos. Conforme ressaltado por Perelman: "aqueles que prestaram alguma atenção

\footnotetext{
${ }^{3}$ PERELMAN, Chaïm. Lógica Jurídica. São Paulo: Martins Fontes, 2000, p. 140.

${ }^{4}$ ALVES, Marco Antônio Sousa. A Nova Retórica de Chaïm Perelman: considerações sobre a racionalidade, a tensão decisionismo/legalismo, e o Estado Democrático de Direito. Trabalho apresentado no Seminário Teoria da Argumentação e Nova Retórica, PUC-MG, Belo Horizonte, 2009.

${ }^{5}$ PERELMAN, Chaïm. Lógica Jurídica. São Paulo: Martins Fontes, 2000, p. 149.
} 
a essas controvérsias não deixaram de reconhecer a existência de certo pluralismo, do qual o senso comum sempre teve consciência"6.

Neste aspecto, visualiza-se que partindo do aceitável, ponto focal concebível universalmente, aproxima-se da razão, e esta, por sua vez, via argumentos concatenados são rompidos e desmascarados, permitindo a fusão em dialética.

O desenvolvimento da retórica conduz a uma simultaneidade de considerações que indicam as preocupações atuais da pragmática, englobando todo o sistema disciplinar. Incluem, nesta multidisciplinariedade, as considerações históricas e atuais, abrangendo os teóricos contemporâneos da argumentação.

A princípio, Chaïm Perelman, autor que revigorou o exame da retórica ao indicar a presença dela em diversas disciplinas, do direito à filosofia, enfatiza o fundamento da teoria como a arte de persuadir, ou o conjunto dos meios verbais destinados a obter ou reforçar a adesão do auditório às teses submetidas a seu assentimento ${ }^{7}$.

Destaca-se que, na antiguidade, durante o império romano, desfrutou a retórica de grande prestígio. Grandes oradores romanos, dentre os quais destacam Cícero e Quintino, contribuíram admiravelmente para a disseminação da retórica, que decaiu após a queda do império romano, ${ }^{8}$ sobrevivendo somente em sua prática.

Nas palavras de Perelman:

A Retórica, que foi elaborada pelos Antigos e à qual foram consagradas as obras muito conhecidas de Aristóteles, Cícero e Quintiliano, é uma disciplina que, após ter sido considerada o coroamento da educação greco-romana, degenerou no século XVI, quando foi reduzida ao estudo das figuras de estilo, e depois desapareceu inteiramente dos programas do ensino secundário ${ }^{9}$.

Restaurada por Perelman, a retórica focalizou a forma e o conteúdo para compreensão da realidade, evidenciada, também, na ontologia, difundindo em argumentos com base na oposição das teses levantadas, oriundas dos valores do senso comum.

\footnotetext{
${ }^{6}$ PERELMAN, Chaïm. Lógica Jurídica. São Paulo: Martins Fontes, 2000, p. 158.

7 PERELMAN, Chaïm; OLBRECHTS-TUTECA, Lucie. Tratado da Argumentação. São Paulo: Martins Fontes, 2002, p. 5.

${ }^{8}$ Após a queda do império romano a retórica foi progressivamente decaindo e, mesmo sobrevivendo como prática, não era considerada enquanto objeto de estudo. Esta tendência foi majorando através do predomínio do pensamento cartesiano, positivista na filosofia e na ciência ocidentais (PERELMAN, Chaïm; OLBRECHTS-TUTECA, Lucie. Tratado da Argumentação. São Paulo: Martins Fontes, 2002, p. 10).

${ }^{9}$ PERELMAN, Chaïm. Lógica Jurídica. São Paulo: Martins Fontes, 2000, p. 141.
} 
Assim, como demonstrativo da fonte da dialética, transcreve-se a constatação da Perelman:

Para os estóicos, especialmente para Epicteto, a existência de um acordo sobre o que qualificam de "prenoções", que são os valores do senso comum, universalmente admitidos, não impede desacordos sobre casos de aplicação, quando se trata de passar dos valores comuns aos comportamentos concretos que deveriam guiar ${ }^{10}$.

Tais considerações afetam a estrutura específica da inércia dos preceitos primários e da base de concordância entre o comunicador e as facetas múltiplas da compreensão, o que possibilita a dialética.

Por derradeiro, merece destaque as inúmeras discussões teóricas sobre a Nova Retórica, em que cogita ser ela o novo paradigma da Justiça. Daí a evidência da matéria para a modernidade e, consequentemente, para a aplicação do direito. Para Perelman o juízo valorativo esteve ausente da filosofia ocidental pela proeminência do raciocínio cartesiano (lógico-dedutivo), sendo este o único considerado científico ${ }^{11}$.

A concepção positivista tinha como consequências inevitáveis o fundamento lógico, os métodos científicos e a razão a problemas de conhecimento puramente teóricos, negando a possibilidade de um uso prático discursivo. Opunha-se, por isso, à tradição aristotélica, que admitia uma razão prática, que se aplica a todos os domínios da ação, desde a ética até a política, e justifica a filosofia como a busca da sabedoria ${ }^{12}$.

Não distante, o postulado apregoa que as relações humanas não se sujeitam ao argumento da indiscutibilidade por serem essencialmente subjetivos, o que afasta a possibilidade de valorizar a razão absoluta.

A premissa não se robotiza, pelo contrário, a conduta prática comporta mais de um resultado ou significado conforme a aceitabilidade por uma ou outra escala de valorativa. Por isso, o mais aceitável, na linha de procedimentos, será aquele que se apresenta como a mais razoável, mediante uma justificativa convincente e plausível.

Em se tratando de relações humanas, nesta forma de pensar, considerando-se como foco o direito, vê-se que o raciocínio dialético privilegia

\footnotetext{
${ }^{10}$ PERELMAN, Chaïm. Lógica Jurídica. São Paulo: Martins Fontes, 2000, p. 132.

${ }^{11}$ O raciocínio cartesiano, criado por René Descartes, tem como base o Ceticismo Metodológico; duvida-se de cada ideia que pode ser duvidada. Ao contrário dos gregos antigos, que acreditavam que as coisas existem sem explicação alguma. Descartes instituía a dúvida. A contribuição de Descartes, com sua nova metodologia foi de extrema importância para a constante busca criteriosa do conhecimento verdadeiro a partir das ciências (COLCHETE, Eliane; MORAIS JUNIOR, Luis Carlos de. A Formação da Filosofia Contemporânea. Rio de Janeiro: Litteris, 2014, p. 121).

${ }^{12} \mathrm{O}$ rompimento dos lanços entre lei e justiça, a noção de razão prática não encontra espaço na determinação da melhor decisão dentre as possibilidades abertas pela lei, cabendo ao arbítrio do juiz dar a palavra final na escolha entre alternativas igualmente aceitáveis do ponto de vista do direito positivo (KELSEN, Hans. Reine Rechislehre. Wien: Franz Deuticke, 1969, p. 353).
} 
a práxis em detrimento de uma solução imposta previamente. Os métodos discursivos são, portanto, o melhor mecanismo para a solução de problemas práticos que envolvem valores.

Por consequência, a dialética, por ser a arte da discussão, se mostra o método apropriado à solução dos problemas práticos, os que concernem aos fins da ação, que envolvem valores; é no exame de tais questões que é empregado nos diálogos socráticos, é esta razão da estima que Platão tem por ela ${ }^{13}$.

Portanto, de modo geral, admissível à concepção de técnicas comuns, visando a solução causais, práticos, prevalecendo os mesmos instrumentos do raciocínio dialético e retórico.

Como explanado inicialmente, a retórica engloba todo o sistema disciplinar, da filosofia ao direito, a fim de ilustração, Roland Barthes demonstra a ligação da retórica com as questões jurídicas da propriedade:

Dá gosto verificar que a arte da palavra está originalmente ligada a uma reivindicação de propriedade, como se a linguagem, na sua qualidade de objeto de uma transformação e condição de uma prática, se tivesse determinado, não a partir de uma subtil mediação ideológica, como certamente aconteceu a tantas outras formas de arte, mas a partir da socialidade mais nua, afirmada na sua brutalidade fundamental, a da possessão de terras: começámos a refletir sobre a linguagem para defendermos os nossos bens ${ }^{14}$.

Perelman argumenta que a retórica promove a reflexão jurídica, por intermédio dos topoi (lugares-comuns), início para a fundamentação decisória com base num específico auditório ${ }^{15}$.

Como destacado, quando da conceituação de retórica, ela está intimamente ligada à dialética. Ela não se enquadra num gênero particular e definido, vai além, seu papel é distinguir o que é verdadeiramente suscetível de persuadir do que é somente aparência. Do mesmo modo que pertence à dialética distinguir o silogismo verdadeiro do silogismo aparente, porque a sofística procede não da faculdade, mas de escolha determinada ${ }^{16}$.

Por derradeiro, as normas jurídicas, por si só, são incapazes de edificar um sistema jurídico completo, e por esta razão sobreleva-se a necessidade de um aparato filosófico e principiológico de caráter aberto. A nova retórica é a grande contribuição para a ciência jurídica, convidativa às reflexões, empregada em todas as áreas do conhecimento, cujo objetivo, em síntese,

\footnotetext{
${ }^{13}$ PERELMAN, Chaïm. Lógica Jurídica. São Paulo: Martins Fontes, 2000, p. 139.

${ }^{14}$ ROLAND BARTHES. L'Aventure Sémiologique. Paris, Seuil, 1985, trad. Maria de Santa Cruz. A Aventura Semiológica, Lx., 70. ed., 1987, p. 24.

${ }^{15}$ PERELMAN, Chaïm. Lógica Jurídica. São Paulo: Martins Fontes, 2000, p. 159.

${ }^{16}$ ARISTÓTELES. Arte Retórica e Arte Poética. Tradução de Antônio Pinto de Carvalho. São Paulo: Difusão Européia do Livro, 1964, p. 22.
} 
é quebrar as fronteiras da razão. Tendo como elemento de argumentação, concebida no sentido mais amplo, como uma preliminar na explanação consagrada ao raciocínio jurídico.

\section{RACIONALISMO MODERNO}

O racionalismo foi um seguimento de pensamento que tem como fundamento o princípio de que é possível chegar às verdades absolutas através da razão, não sendo iludido pela emoção. Busca alcançar a verdade pura, tendo como base o preceito de que os sentidos humanos podem ser iludidos ou enganados por diversos fatores externos, no entanto, a razão não se submete aos sentidos, podendo perceber a realidade através do pensamento racional. A doutrina enfatiza que o único órgão adequado ou completo do conhecimento é a razão, de modo que todo o conhecimento verdadeiro tem origem racional.

O fundamento epistemológico busca fortalecer a razão como pressuposto do conhecimento humano, enquadra o racionalismo como a principal fonte de descoberta humana. Segundo o modo de ver do racionalismo, um conhecimento só merece realmente esse nome se for necessário e tiver validade universal. Se minha razão julga que deve ser assim, que não pode ser de outra forma, por isso, deve ser assim sempre e em toda parte, então (e só então), estamos lidando com um conhecimento autêntico ${ }^{17}$.

Essa racionalidade moderna, que privilegia a razão, passou a considerar verdadeiro somente o que é lógico, preciso e capaz de ser confirmado cientificamente, o principio denomina-se como racionalismo gnoseológico ou epistemológico.

Reflexo dessa doutrina é a influência no modo de pensar as ciências e, inclusive, o direito na modernidade. O racionalismo situou a razão no centro do universo, impondo a busca da verdade absoluta e valorizando a lógica formal em detrimento da retórica ${ }^{18}$.

Perelman, expondo a colisão do racionalismo com a retórica, indica a evidência como ponto de partida desta:

Descartes e os racionalistas puderam deixar de lado a retórica na medida em que a verdade das premissas era garantida pela evidência, resultante do fato de se referirem a idéias claras e distintas, a respeito das quais nenhuma discussão era possível. Pressupondo a evidência do ponto de partida, os racionalistas desinteressaram-se de todos os problemas levantados pelo manejo de uma linguagem ${ }^{19}$.

\footnotetext{
${ }^{17}$ HESSEN, Johannes. Teoria do Conhecimento. Tradução: João Vergílio Gallerani Cuter, São Paulo: Martins Fontes, 2000, p. 36.

${ }^{18}$ TEIXEIRA, J. P. A. Racionalidade das Decisões Judiciais. São Paulo: Editora Juarez de Oliveira, 2002, p. 14.

${ }^{19}$ PERELMAN, Chaïm. Lógica Jurídica. Nova Retórica. São Paulo: Martins Fontes, 2000, p. 142.
} 
Esse segmento de pensamento não é fruto somente na modernidade, pois sua gênese está na origem do pensamento acidental com os filósofos da natureza já no século VI a.C.. Heráclito, julgando que o homem tem dois instrumentos para o conhecimento da verdade, a saber: a sensação e a razão, considerou a primeira não digna de fé, fazendo, por isso, da razão o critério de verdade ${ }^{20}$.

Bornheim, esclarecendo a relação entre Deus e a razão, objetivando demonstrar o elo que funda na divindade, expõe:

[...] para os homens são os olhos e ouvidos se suas almas são bárbaras, o que é como se tivesse dito: São as almas bárbaras que confiam na percepção sensível, desprovida de razão. Explica a razão como critério da verdade, mas não qualquer razão indiferentemente e sim a comum e divina. Elucido o que com isso quer dizer. Pois este filósofo sustenta que é dotado de razão e apto de pensamento o que nos cerca [...] Esta razão divina, conforme Heráclito, nós a aspiramos, tornando-nos assim aptos ao pensamento, inconscientemente quando dormimos, conscientemente quando acordados. Pois, fechando-se as aberturas de nossos órgãos sensíveis durante o sono, desliga-se o espírito em nós de sua relação com o que nos cerca; só permanece a relação através do respirar, como uma espécie de raiz $^{21}$.

Este período histórico teve o predomínio da cultura teocêntrica, onde a ciência baseava na fé, cujo objetivo era apenas a compreensão do natural sem o fim de exercer o controle científico, demonstrando que a figura de Deus era o meio de atingir a vida eterna.

$\mathrm{Na}$ antiguidade a visão do mundo dominante na Europa, assim como na maioria das outras civilizações, era orgânica. As pessoas viviam em comunidades pequenas e coesas, vivenciavam a natureza em relações caracterizadas pela interdependência dos fenômenos espirituais e materiais e pela subordinação de necessidades individuais às da comunidade. A estrutura científica dessa visão de mundo orgânica assentava em duas autoridades: Aristóteles e a Igreja. No século XIII, Tomás de Aquino combinou o abrangente sistema da natureza de Aristóteles com a teologia e a ética cristãs e, assim fazendo, estabeleceu a estrutura conceitual que permaneceu inconteste durante toda a Idade Média. A natureza da ciência medieval era muito diferente daquela da ciência contemporânea. Baseava-se na razão e na fé, e sua principal finalidade era compreender o significado das coisas e não exercer a predição ou o controle ${ }^{22}$.

\footnotetext{
${ }^{20}$ MONDIM, Battista. Curso de Filosofia. 10. ed., São Paulo: Paulus, 1981, p. 27.

${ }^{21}$ BORNHEIM, Gerd. Sobre o Estatuo da Razão. In: NOVAES, Adauto (org). A Crise da Razão. Rio de Janeiro: Fundação Nacional de Arte, 1996, p. 97.

${ }^{22}$ CAPRA, Fritjof. O Ponto de Mutação. A Ciência, a Sociedade e a Cultura Emergente. 24. ed., São Paulo: Editora Cultrix, 2003, p. 49.
} 
O racionalismo, num breve período, tem em Deus um mecanismo que assinala a passagem da evidência à verdade objetiva, a superação dos confins da subjetividade, para a qual a dúvida parecia limitar o conhecer. Provada a existência de Deus era possível sobre ela motivar a verdade objetiva do mundo: Deus é garantia do critério da evidência ${ }^{23}$.

René Descartes, fundador do racionalismo moderno ${ }^{24}$, estorna da teoria a experiência, sintetizando uma verdadeira reforma na história do conhecimento humano por ter submetido uma crítica sistemática a toda herança cultural, filosófica e científica de sua época, consolidou a compreensão de que o centro é a razão e não mais o ser ou Deus ${ }^{25}$. Portanto, a consagração do racionalismo como um seguimento de pensamento, tendo como fundamento o princípio de que é possível chegar às verdades absolutas somente através da razão.

Potencializa a razão humana como o único meio idóneo para se chegar à verdade e construir a ciência. Dentre suas teorias, sobreleva a do método cartesiano, que sustenta o caráter universal e absoluto da razão que, partindo do cogito $^{26}$ e utilizando-se das noções, pode chegar a descobrir todas as verdades possíveis ${ }^{27}$.

Contrapondo o racionalismo, Pascal descreve que a razão tem como limite o homem, pois, não é possível explicar o mundo humano, moral e o religioso. O conhecimento não racional possui percepção que a razão não alcança, ou seja, a razão do coração, o que confirma a fragilidade da razão humana visto pela sua insuficiência.

Pascal comprova que a consciência dos limites e a consciência da insatisfação representam a nobreza do homem. Este não é só razão, não é redutível a uma ideia clara e distinta, mas é coração e sentimento:

O coração tem suas razões, que a razão não conhece: Percebe-se isso em mil coisas. Digo que o coração ama o ser universal naturalmente e a si mesmo naturalmente, conforme aquilo a que se aplique; e ele se endurece contra um ou outro, à sua escolha. Conhecemos a verdade não só pela razão mas também pelo coração; é desta última maneira que conhecemos os princípios, e é em vão que o raciocínio, que deles não participa, tenta combatê-los ${ }^{28}$.

\footnotetext{
${ }^{23}$ COTTINGHAM, John. A Filosofia de Descartes. Trad. Maria do Rosário Sousa Guedes. Rio de Janeiro, 70. ed., 1989.

${ }^{24}$ DESCARTES, René. Discurso do Método. São Paulo: Abril Cultura, 1973. Coleção Os Pensadores, vol. XV.

${ }^{25}$ REALE, Giovanni; ANTISERI, Dario. História da Filosofia, São Paulo: Métodos, v. 3, p. 283.

${ }^{26}$ Cogito, ergo sum, significa "penso, logo existo"; ou ainda Dubito, ergo cogito, ergo sum: "Eu duvido, logo penso, logo existo".

${ }^{27}$ ABBAGNANO, Nicola. Dicionário de Filosofia. Tradução de Alfredo Bosi, revisada por Ivone Castilho Benedetti. São Paulo: Martins Fontes, 2003, p. 118.

${ }^{28}$ PASCAL, Blaise. Pensamentos. Tradução de Sérgio Milliet. 2. ed., São Paulo: Abril Cultural, 1979, p. 107.
} 
Percebe-se que o racionalismo, oriundo de uma doutrina histórica, a qual construía a razão como critério de verdade ligado à Deus, tinha a existência do criador assinalada pela passagem da evidência à verdade objetiva, e a superação dos confins da subjetividade. E, mantendo o postulado primitivo, fundamenta-se como o único órgão adequado ou completo do conhecimento, de modo que toda a compreensão da verdade tem origem racional. Consequentemente, e em paralelo com a modernidade, ao excluir o caráter subjetivo o racionalismo rompe com a retórica, repudiando a possibilidade argumentativa.

Nesta perspectiva, o racionalismo, desprovido de finalidade interpretativa, não tem caráter de desvendar os anseios sociais, porém delimita os preceitos legais que norteariam a atuação do aplicador da norma, cria um imenso componente autoritário, correspondendo a um modelo político propenso mais às tiranias do que a um regime democrático.

O sistema burocrático e genérico, com finalidade de proclamar a certeza, utilizando-se de fórmulas pré-estabelecida, o qual arruinava a racionalidade. O que aponta com veemência a lição de Baptista:

Referimo-nos ao predomínio absoluto do valor segurança, em detrimento do valor justiça, enquanto polaridades antagônicas, na constituição da idéia de Direito, e a formação do espírito científico moderno, em sua avassaladora conquista de todos os territórios culturais do Ocidente, de que resultou a completa submissão do pensamento jurídico aos métodos e princípios das ciências da natureza, ou das ciências lógicas, como a matemática ${ }^{29}$.

Portanto, o racionalismo tem como fundamento o princípio de que é possível chegar às verdades absolutas somente pela razão, rompendo, assim, com a dialética. Os racionalistas deixam de lado a retórica utilizando-se das evidências como mecanismo de formação de certeza. E com isso, na aplicação da justiça, predisposta a dar parâmetro e equilíbrio à sociedade, ou, a menos, amenizar as desigualdades sociais, exclui a possibilidade de análise subjetiva como instrumento capaz de atingir essa finalidade.

\section{A PROBLEMÁTICA DA APLICAÇÃO DA JUSTIÇA}

A necessidade humana por respostas e conclusões precisas para os problemas que circundam a existência do indivíduo, soluções igualitárias e lógicas para os conflitos sociais, o clamor por justiça, que na visão popular se materializa pelo posicionamento célere da máquina estatal, substanciada em posições satisfativas capaz de saciar os anseios individuais e coletivos, são fatores que impulsionam o estudo e as pesquisas científicas no campo da aplicação do justo.

${ }^{29}$ SILVA, Ovídio A. Baptista. Processo e Ideologia: o paradigma racionalista. Rio de Janeiro: Forense, 2006, p. 89. 
Épocas que a globalização orquestra a vida das pessoas, conduzindo à agilidade física e mental, uma sociedade robotizada, contudo, adaptada à velocidade científica, que de forma autômato impulsiona a expansão do conhecimento científico. Nos dias de hoje restam poucas alternativas à sociedade, e dentre elas, a vida em sincronia com o tempo prevalece sobre as demais, de forma que as satisfações dependem de respostas precisas em harmonia com a hermenêutica.

Essa evolução, pelo contrário que se pensa, fomenta a desigualdade, trazendo a desordem e o subdesenvolvimento. Ou seja, desenvolvimento numa extremidade e subdesenvolvimento na outra, são partes integrantes do reflexo do mesmo sistema histórico, fatores que impulsionam o fracasso da natureza dos seres.

$\mathrm{Na}$ temática, Alessandro Severino Vallér Zenni, traçando um panorama sobre as desigualdades brutais na pós-modernidade, apregoa:

Ao notarmos o caos instalado no planeta por decorrência de uma situação de subdesenvolvimento e miséria abissais em boa parte do mundo globalizado, chegando ao angustiante resultado de que o ser humano conduz-se à estagnação à medida do curso do tempo, frustrando o seu projeto ontológico que imprescinde do outro para concretizar-se ${ }^{30}$.

Perquiri se a causa desse caos seria a globalização, como processo revolucionário, que, embora tenha evoluído paulatinamente, trazendo consequências no âmbito social, cultural, econômico e principalmente jurídico, seria o vilão que desencadeou a crise que carrega a sociedade frustrando esse projeto ontológico.

Nessa perspectiva, o direito é o instrumento social apto a proporcionar respostas e minimizar as divergências. Esta importância da ciência jurídica para a completa supressão dos anseios individuais e coletivos é a fonte que reúne a filosofia às normas.

O Direito, dentre os mais diversos exemplos de conhecimento especializado, é aquele que mais diretamente interessa ao sistema social, pois é ele, em regra, uma técnica de controle de comportamento, seja proibindo, obrigando ou permitindo determinadas ações ou, até mesmo, na imposição da pena àqueles que não se comportam de acordo com a norma.

Há uma necessidade de regular as condutas dos membros da sociedade visando à harmonia, e dentre esses controles podemos destacar a moral, a religião, as regras de trato social. Na lição de Paulo Nader:

O mundo primitivo não distinguiu as diversas espécies de ordenamentos sociais. O Direito absorvia questões afetas ao plano da consciência,

${ }^{30}$ ZENNI, Alessandro Severino Vallér. A Crise do Direito Liberal na Pós-Modernidade. Porto Alegre: Sergio Antonio Fabris Editor, 2006, p. 62. 
própria da moral e da religião, e assuntos não pertinentes à disciplina e equilíbrio da sociedade, identificados hoje por usos sociais ${ }^{31}$.

Uma marcante diferenciação dessas esferas normativas se sobrepõe mantendo os meios de controle em sua específica atuação com seu peculiar objeto. E, pela compreensão, vê-se que a faixa de atuação do direito é traçar linhas da conduta social, pleiteando à ordem e o bem comum.

O direito regula os fatos sociais mais relevantes para o convívio social, ele não visa o aperfeiçoamento interior do homem; essa meta pertence à moral. Não pretende preparar o ser humano para uma vida ligada a Deus, esta finalidade é buscada pela religião. Nem se preocupa em incentivar a cortesia, o cavalheirismo ou as normas de etiqueta, campo específico das regras de trato social, que procuram aprimorar o nível das relações sociais ${ }^{32}$.

No âmbito jurídico, o grande dilema é a famosa aplicação da justiça e as variáveis discussões existentes quanto aos fundamentos do direito, e a linha divisionária entre o legalismo e a moral, fatores que sopesarão na decisão judicial, ${ }^{33}$ bem como a problemática da discordância entre aplicação da lei, com apego exagerado às suas formalidades, e a justiça, em seu sentido equitativo e moral, que são heranças do positivismo jurídico desenvolvido no século XIX que, por sua vez, foi uma aplicação degenerada de um preceito antigo ${ }^{34}$.

Sustentava que lei positiva mantinha a possibilidade de uma solução para todos os eventuais casos ou ocorrências da vida social, bastando interpretar o direito, a legislação era a saída para tudo, sendo a função do jurista a mera extração do sentido pleno dos textos, para compreender o significado, ordenar as conclusões parciais e atingir as grandes sistematizações ${ }^{35}$.

Norberto Borbbio ressalta os valores que inspiram a ordem jurídica em seu âmbito deontológico de validade, em paralelo ao sistema ontológico.

O problema da justiça é o problema da correspondência ou não da norma aos valores últimos ou finais que inspiram determinado ordenamento jurídico. [...] Colocar-se o problema da justiça ou não de uma norma equivale a se colocar o problema da correspondência entre o que é real e o que é ideal. Por isso costuma-se chamar o problema da justiça de problema deontológico do direito ${ }^{36}$.

\footnotetext{
${ }^{31}$ NADER, Paulo. Introdução ao Estudo do Direito. 28. ed., Rio de Janeiro: Forense, 2007, p. 31.

${ }^{32}$ BETIOLI, Antônio Bento. Introdução ao Direito: lições de propedêutica jurídica tridimensional. 10 ed., São Paulo: Saraiva, 2008, p. 89.

${ }_{33}$ STRECK, Lenio Luiz. Hermenêutica Jurídica em Crise: uma exploração hermenêutica da construção do Direito. 6. ed., Porto Alegre: Livraria do Advogado, 2005, p. 236.

${ }^{34}$ BOBBIO, Norberto. Teoria Geral do Direito. 3. ed., São Paulo: Martins Fontes, 2010. p. 275.

${ }^{35}$ REALE, Miguel. Lições Preliminares de Direito. 27. ed., São Paulo: Saraiva, 2009, p. 280.

${ }^{36}$ BOBBIO, Norberto. Teoria Geral do Direito. 3. ed., São Paulo: Martins Fontes, 2010. p. 38.
} 
Portanto, seria impossível excluir da aplicação da lei a análise mecanizada do positivismo e a arbitrariedade do sistema jurídico, em colisão com a retórica em busca de decisão coerente com o verdadeiro significado de justiça, a faceta é entender o ordenamento em seu caráter valorativo.

E ainda, visualizando a lei como medida dos atos humanos, mecanismo de seriedade e instrumento de proporcionar felicidade, Alessandro Severino Vallér Zenni, referindo-se a lei como garantia da ordem social, propõem:

Com o fim último da razão humana é a felicidade e o bem, necessariamente a lei, projeto racional, aponta à ondenação e à beatitude. Como a parte ordena ao todo, sendo o homem parte da natureza, integrante da comunidade, e o escopo da lei está na perfeição e beatitude, deve ordenar as relações de todos os membros da comunidade para o bem, isto significa que toda lei visa o bem comum ${ }^{37}$.

Chaïm Perelman, descrevendo a igualdade formal no pensamento positivista, relata a impossibilidade de definir justiça pela lógica formal. $\mathrm{Na}$ aplicação da lei, por ela não ser estagnada, depende de valoração:

O que parece justificar o ponto de vista positivista é que, graças à experiência e à demonstração, pode-se estabelecer a verdade de certos fatos e de certas proposições, lógica, matemáticas, enquanto os juízos de valor permanecem controvertidos, sem que seja possível encontrar um método racional que permita estabelecer um acordo a respeito deles [...] De fato, se nos ativermos ao método positivista, a idéia de uma escolha, de uma decisão, de uma solução razoável, que implique a possibilidade do uso prático da razão, deverá ser excluída. Mas mesmo que fôssemos além da abordagem positivista, não bastava desejar uma concepção mais ampla da razão: cumpria também elaborar uma metodologia que permitisse pô-la em prática, elaborando uma lógica dos juízos de valor que não os fizesse depender do arbítrio de cada um ${ }^{38}$.

O positivismo jurídico, em síntese, como escola jurídico-filosófica tem por referência a conexão do direito à posição de ciência e a oposição ao jusnaturalismo, tendo o direito como resultado de um conjunto de valores e princípios que seriam dependentes da norma oriunda do Estado.

É uma corrente da teoria do direito que procura explicar o fenômeno jurídico a partir do estudo das normas positivadas, ou seja, daquelas normas postas pela autoridade soberana de determinada sociedade. Ao definir o direito, o positivismo identifica o conceito como mandamento efetivamente posto pelas autoridades que possuem o poder político de criar as normas jurídicas ${ }^{39}$.

\footnotetext{
${ }^{37}$ ZENNI, Alessandro Severino Vallér. A Crise do Direito Liberal na Pós-Modernidade. Porto Alegre: Sergio Antonio Fabris Editor, 2006, p. 90.

${ }^{38}$ PERELMAN, Chaïm. Lógica Jurídica. Nova Retórica. São Paulo: Martins Fontes, 2000, p. 136.

${ }^{39}$ DIMOULIS, Dimitri. Positivismo Jurídico. São Paulo: Método, 2006.
} 
Luís Roberto Barroso, demonstrando o controle do Estado sobre a sociedade, tendo como mecanismo o direito, passa a expor:

A lei passa a ser vista como expressão superior da razão. A ciência do Direito, ou, também, teoria geral do Direito, dogmática jurídica, é o domínio asséptico da segurança e da justiça. O Estado é a fonte única do poder e do Direito. O sistema jurídico é completo e autossuficiente ${ }^{40}$.

$E$, em sequência, na hermenêutica de Kelsen, há críticas às posturas positivistas do século XIX, referido a insuficiência de elementos concretos capaz de chegar a decisão certa, imutável e invariável, e assim descreve:

A questão de saber qual é, de entre as possibilidades que se apresentam nos quadros do Direito a aplicar, a correta, não é sequer, segundo o próprio pressuposto de que se parte, uma questão de conhecimento dirigido ao Direito positivo, não é um problema de teoria do direito, mas um problema de política do Direito. A tarefa que consiste em obter, a partir da lei, a única sentença justa (certa) ou o único ato administrativo correto é, no essencial, idêntica à tarefa de quem se proponha, nos quadros da Constituição, criar as únicas leis justas (certas). Assim como da Constituição, através de interpretação, não podemos extrair as únicas leis corretas, tampouco podemos, a partir da lei, por interpretação, obter as únicas sentenças corretas ${ }^{41}$.

Com essas considerações trás a problemática da aplicação da justiça com amplos aspectos conceituais; justiça, no significado de aplicação da lei e igualdade, como princípio básico que objetiva manter a ordem social através da preservação dos direitos em sua forma legal.

$E$, nessa perspectiva, Aristóteles expõe que o termo justiça significa legalidade e igualdade, em conexão. Assim, justo é tanto aquele que cumpre a lei (justiça em sentido estrito) quanto àquele que realiza a igualdade (justiça em sentido universal) ${ }^{42}$. Portanto, os problemas sociais, o subdesenvolvimento, o direito como instrumento e controle social, positivismo a dialética, são facetas que, intercaladas, refletem a forma de aplicação do justo.

Somente a lei pura (positivada), como elemento modelador da sociedade, não dá subsídio para certificarmos se sua aplicação será verdadeiramente justa. Considerando que o direito é meio de regular a condutas dos membros da sociedade, visando à harmonia, e sabendo que ele é fruto da história.

\footnotetext{
${ }^{40}$ BARROSO, Luís Roberto. Fundamentos Teóricos e Filosóficos do Novo Direito Constitucional Brasileiro (pós-modernidade, teoria crítica e pós-positivismo). Revista Diálogo Jurídico, Salvador: CAJ - Centro de Atualização Jurídica, v. I, nº 6, set. 2001.

${ }^{41}$ KELSEN, Hans. Teoria Pura do Direito. 6. ed., Tradução de João Baptista Machado. São Paulo: Martins Fontes, 1998, p. 392.

${ }^{42}$ FREITAS, Juarez. As Grandes Linhas da Filosofia do Direito. 3. ed., Rio Grande do Sul: EDUCS, 1986. p. 114.
} 
A problemática de aplicação do justo, nesta perspectiva, vai além da pura aplicação da lei.

Karl Marx, produz uma tese em que o Direito, como postulado de conduta coercitiva, surge da ideologia da classe dominante, que é concebido da burguesia. O Direito é compreendido como síntese de um processo dialético de conflito de interesses entre as classes sociais, denominada por Marx de luta de classes. Indica que sendo o direito criação do homem seu fundamento é o próprio homem, portanto, a instrumentalidade das leis seria o meio de manipulação, em favor de uma determinada classe, que se beneficia com a norma legal ${ }^{43}$.

O direito não é um acontecimento neutro, é iminente de lutas de classe, afastado do idealismo, contudo, vinculado à prática. A premissa se confirma quando ocorre uma revolução, a primeira mudança é na órbita jurídica, que adaptará a outros interesses ${ }^{44}$.

Complementando da seguinte forma:

As normas jurídicas e os ordenamentos jurídicos, como todos os atos normativos editados pelo poder de um dado Estado, traduzem de forma explícita, seja em seu conteúdo, seja pelas práticas que o sustentam, as características, interesses, e ideologia dos grupos que legislam ${ }^{45}$.

Portanto, limitar a uma corrente legal como forma de controle social, seja via aplicação da lei ou mediante postulados dirigentes, coercitivos ou não, é tarefa um tanto quanto lacunosa. Como conciliar o positivismo, legalismo, junto com os anseios sociais e o equilíbrio entre a aplicação do direito e a justiça, com as instituições e os sistemas de regras, objetivando a equidade, sem colocar a lei em detrimento da sociedade? O modelo é proposto por Perelman, que traz: "É a dialética entre o legislativo e o poder judiciário, entre a doutrina e a autoridade, entre o poder e a opinião pública, que faz a vida do direito e the permite conciliar a estabilidade e a mudança"46.

\section{CONSIDERAÇÕES FINAIS}

A compreensão do sistema que cerca a existência do homem com suas peculiaridades dentro de uma realidade solada pelas desigualdades sociais; crises econômicas, subdesenvolvimento, fragilidade do ser frente à necessidade de uma existência sadia, são frutos da longa construção histórica. São diversos os fatores causadores desta problemática a qual reflete significativamente

\footnotetext{
${ }^{43}$ COMPARATO, Fábio Konder. Fundamentos dos Direitos Humanos. In Cultura dos Direitos Humanos. São Paulo, p. 60.

${ }^{44}$ AGUIAR, Roberto A. R. O que é Justiça: uma Abordagem dialética. 5. ed., São Paulo: Alfa-ômega, 1999, p. 116.

${ }^{45}$ AGUIAR, Roberto A. R. O que é Justiça: uma Abordagem dialética. 5. ed., São Paulo: Alfa-ômega, 1999, p. 115.

${ }^{46}$ PERELMAN, Chaim. A Interpretação Jurídica. In: Ética e Direito. Tradução de Maria Ermantina Galvão. São Paulo: Martins Fontes, 1996, p. 631.
} 
no intento de vida de cada ser, frustrando o seu projeto ontológico. Vários mecanismos de contenção poderiam ser levantados tendentes a remediar a atual situação de miserabilidade social, que inclui a física e mental, contudo, o diálogo das fontes mostra-se mais coerente frente a situação social atual. O direito, como sistema de normas de conduta imposto para regular as relações sociais, somado a outras fontes do conhecimento, faz parte do equilíbrio humanitário proporcionador de justiça.

Não distante a existência memorável do direito nas sociedades humanas e de sua estreita relação com a civilização, este se propõe a controlar comportamentos, seja proibindo, obrigando ou permitindo determinadas ações, consequentemente, é a fórmula tendente a fazer justiça, oferecendo para minimizar a problemática, criando mecanismo de contenção e instrumentos capaz de reduzir a desigualdade.

A racionalidade moderna privilegia a razão, considera verdadeiro somente o que é lógico e preciso. O racionalismo como seguimento de pensamento que tem como fundamento o princípio de que é possível chegar às verdades absolutas somente pela razão, acaba por romper com a dialética.

Porém, em contradição, a retórica se destaca pelo caráter aberto, cujo postulado apregoa que as relações humanas não se sujeitam ao argumento da indiscutibilidade por serem essencialmente subjetivos, repudiando as normas jurídicas, pela incapacidade de edificar um sistema jurídico completo, e consequentemente, vencer as desigualdades sociais, e, por esta razão, destaca a necessidade de um aparato filosófico e principiológico.

A construção de um novo paradigma, intensificando as discussões em torno da justiça, é a conclusão mais valorada, este mecanismo deve ser criado pela junção multidisciplinar das áreas do conhecimento. O racionalismo moderno deve ser somado à retórica, valorando a dialética entre o legislativo e o poder judiciário, entre a doutrina e o aplicador da lei, entre o poder e a opinião pública, que faz a vida do direito e lhe permite conciliar a estabilidade e a fornecer mudanças.

\section{REFERÊNCIAS}

ABBAGNANO, Nicola. Dicionário de Filosofia. Tradução de Alfredo Bosi. Revisada por Ivone Castilho Benedetti. São Paulo: Martins Fontes, 2003.

AGUIAR, Roberto A. R. O que é Justiça: uma Abordagem dialética. 5. ed., São Paulo: Alfa-ômega, 1999.

ALVES, Marco Antônio Sousa. A Nova Retórica de Chaïm Perelman: considerações sobre a racionalidade, a tensão decisionismo/legalismo, e o Estado Democrático de Direito. Trabalho apresentado no Seminário Teoria da Argumentação e Nova Retórica, PUC-MG, Belo Horizonte, 2009.

ARISTÓTELES. Arte Retórica e Arte Poética. Tradução de Antônio Pinto de Carvalho. São Paulo: Difusão Européia do Livro, 1964.

BETIOLI, Antônio Bento. Introdução ao Direito: lições de propedêutica jurídica tridimensional. 10. ed., São Paulo: Saraiva, 2008. 
BOBBIO, Norberto. Teoria Geral do Direito. 3. ed., São Paulo: Martins Fontes, 2010.

CAPRA, Fritjof. O Ponto de Mutação. A Ciência, a Sociedade e a Cultura Emergente. 24. ed., São Paulo: Editora Cultrix, 2003.

COTTINGHAM, John. A Filosofia de Descartes. Trad. Maria do Rosário Sousa Guedes. 70. ed., Rio de Janeiro: Jorge Zahar, 1989.

DESCARTES, René. Discurso do Método. São Paulo: Abril Cultura, 1973. Coleção Os Pensadores, vol. XV.

DIMOULIS, Dimitri. Positivismo Jurídico. São Paulo: Método, 2006.

FREITAS, Juarez. As Grandes Linhas da Filosofia do Direito. 3. ed., Rio Grande do Sul: EDUCS, 1986.

HESSEN, Johannes. Teoria do Conhecimento. Trad. João Vergílio Gallerani Cuter. São Paulo: Martins Fontes, 2000.

KELSEN, Hans. Teoria Pura do Direito. 6. ed., Tradução de João Baptista Machado. São Paulo: Martins Fontes, 1998.

MONDIM, Battista. Curso de Filosofia. 10. ed., São Paulo: Paulus, 1981.

NADER, Paulo. Introdução ao Estudo do Direito. 28. ed., Rio de Janeiro: Forense, 2007.

PASCAL, Blaise. Pensamentos. Tradução de Sérgio Milliet. 2. ed., São Paulo: Abril Cultural, 1979, p. 107.

PERELMAN, Chaïm. Lógica Jurídica, Nova Retórica. São Paulo: Martins Fontes, 2000.

REALE, Miguel. Lições Preliminares de Direito. 29. ed., São Paulo: Revistas dos Tribunais, 2009.

SILVA, Ovídio A. Baptista da. Processo e Ideologia: O paradigma racionalista. Rio de Janeiro: Forense, 2006.

STRECK, Lenio Luiz. Hermenêutica Jurídica em Crise: uma exploração hermenêutica da construção do Direito. 6. ed., Porto Alegre: Livraria do Advogado, 2005.

TEIXEIRA, J. P. A. Racionalidade das Decisões Judiciais. São Paulo: Editora Juarez de Oliveira, 2002.

ZENNI, Alessandro Severino Vallér. A Crise do Direito Liberal na Pós-Modernidade. Porto Alegre: Sergio Antônio Fabris Editor, 2006. 